Brit. F. vener. Dis. (1971) 47, 54

\title{
Hutchinson's teeth and early treatment of congenital syphilis
}

\author{
W. K. BERNFELD \\ Dewi Sant Hospital, Pontypridd, Glam.
}

Stokes and Gardner (1923) described the case of a girl with congenital syphilis who was treated with six injections of arsphenamine at the age of 5 months; 5 years later, when the Wassermann reaction was repeatedly negative, the authors demonstrated Hutchinson's characteristics radiologically in the unerupted upper central incisors.

The incidence of typical dental stigmata in patients with prenatal syphilis was said by Bradlaw (1953) to range from less than 6 to 23.5 per cent. in upper central incisors and from 3 to 37 per cent. in first molars. Bradshaw also stated:

'Theoretical considerations support the hypothesis that the tooth germs are affected before calcification begins. Those of the affected teeth develop approximately between the fourth and sixth months in utero, which is exactly the time when placental changes permit foetal infection to take place'.

Rajam and Rangiah (1958) saw an 11-year-old boy who, in 1945, starting at the age of 1 month, had received twenty weekly injections for congenital syphilis. He presented Hutchinson's upper central incisors and positive results to the $T$. pallidum immune adherence (TPIA) and intradermal treponemal antigen tests, but a negative VDRL test.

Putkonen and Paatero (1961) examined the $X$-ray appearances of unerupted teeth in 42 patients with congenital syphilis, whose ages ranged from 13 months to 6 years and 11 months. The unerupted upper central incisors of thirteen patients ( 31 per cent.) were interpreted as Hutchinson's teeth. Seven of these children could be re-examined after the second dentition, and in all of them the erupted teeth confirmed the previous $X$-ray findings. In a

Received for publication July 13, 1970 further nine cases of the original series, the $x$ rays had shown possible syphilitic changes; five were traced in a follow-up study, and Hutchinson's teeth were found in only one of them.

Putkonen (1962) investigated the dental changes in 254 patients with congenital syphilis and reportedco as follows:

'44.7 per cent. had syphilitic upper central incisors and 22 per cent. bud molars. The patients with bud molars included 80 per cent. who also had syphilitic upper centrals'.

In a further study, Putkonen (1963) found that, of thirty children whose syphilitic mothers had received penicillin during the latter half of pregnancy, none showed definitely syphilitic upper central incisors or bud molars. He followed up a further series of 36 children admitted to hospital with congenital syphilis during the first few months of life. None of the 21 patients treated during the first 3 months developed distinct syphilitic changes in the permanent teeth, but such changes were present in seven of the other fifteen children in whom treatment was begun during the fourth month or later. In addition, there were possible syphilitic changes in the permanent upper incisors of three patients in whom treatment was started when they were 71 days (two cases) and 72 days old.

\section{Case report}

A baby boy, born on October 28, 1962, was admitted to the East Glamorgan Hospital as an emergency on January 11, 1963, when he was 75 days old.

\section{Examination}

He was suffering from dysphagia, difficulty in breathing, and a blood-stained nasal discharge. The spleen was much 
enlarged, and the haemoglobin showed increasingly low levels. The blood Wassermann and Price's precipitation reactions were strongly positive on three occasions, but the Wassermann reaction in the cerebrospinal fluid was negative. $X$ rays of tibiae and wrists showed multiple separation of the epiphyses and saw-tooth metaphyses. The patient was one of the sixteen cases of early congenital syphilis reported in England and Wales for 1963 (see Chief Medical Officer's report, 1970).

\section{Treatment}

Starting on the day of admission, he was given 250,000

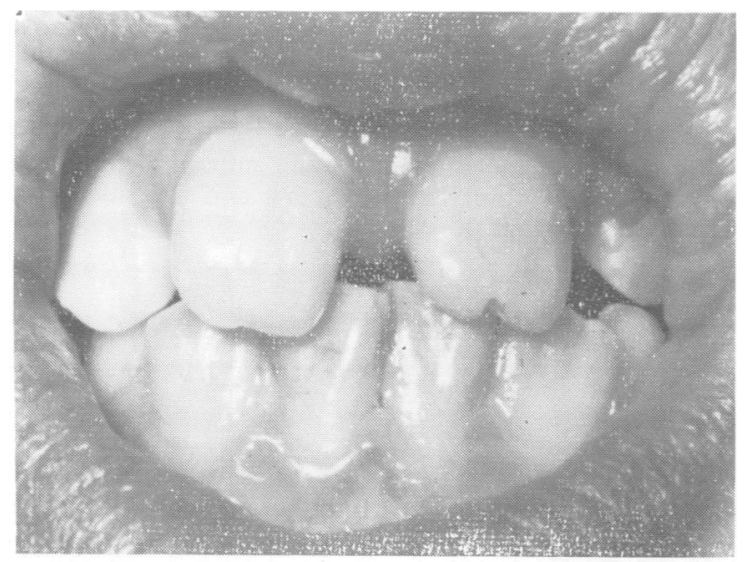

FIG . 1

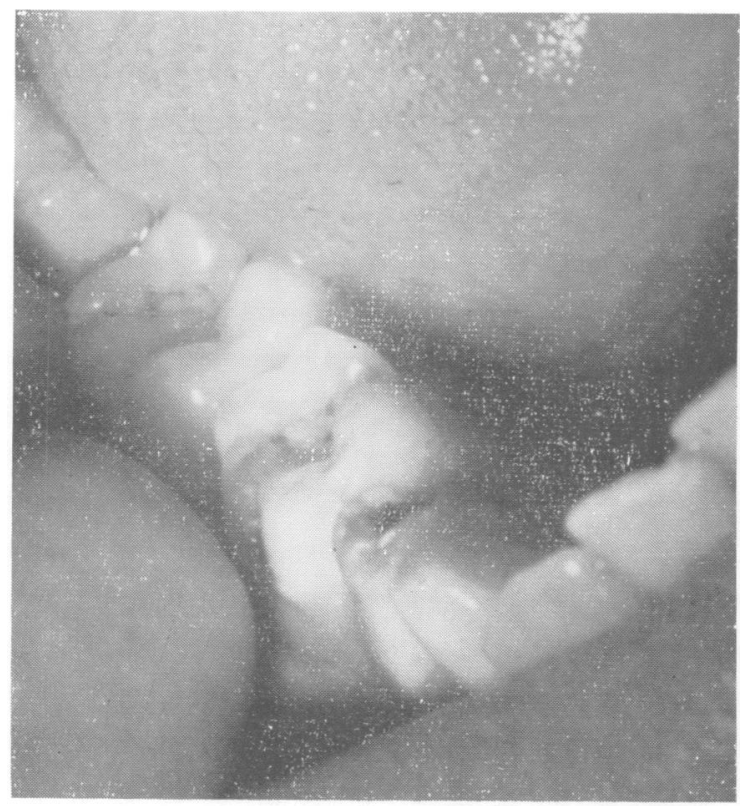

FIG . 2 units of penicillin 4-hourly for almost 3 weeks, a total of $\overrightarrow{\vec{D}}$ about 25 mega units. He stayed in hospital for 7 weeks.

\section{Progress}

When he was $6 \frac{1}{2}$ months old, he appeared clinically normal, and the Wassermann and Price's precipitation reactions had become and remained negative.

In November, 1967, when he was 5 years old, the cardiolipin Wassermann reaction and the treponemal immobilization and Reiter protein complement-fixation tests gave negative results.

On April 6, 1970, he was found to have Hutchinson's teeth (Fig. 1). Professor B. E. D. Cooke, who reviewed the photographs, believes that the first permanent molars are within normal range (Figs 2 and 3 ).

Tests on the patient's mother at first showed strongly positive results to the Wassermann and Price's precipitation reactions, which became and remained negative after she had been given 10 m.u. penicillin and a course of bismuth. She was re-treated with penicillin during her two subsequent pregnancies, but in 1970 results of the TPI, TPHA, and FTA-ABS tests were still positive.

Case-holding was a little difficult, but the boy's father co-operated by catching gonorrhoea in 1967. This brought the whole family back to Pontypridd Clinic. The father' originally strongly positive results to standard tests became negative after a course of penicillin and bismuth, but in 1970 he was still seropositive with the TPI, TPHA, and FTA-ABS tests.

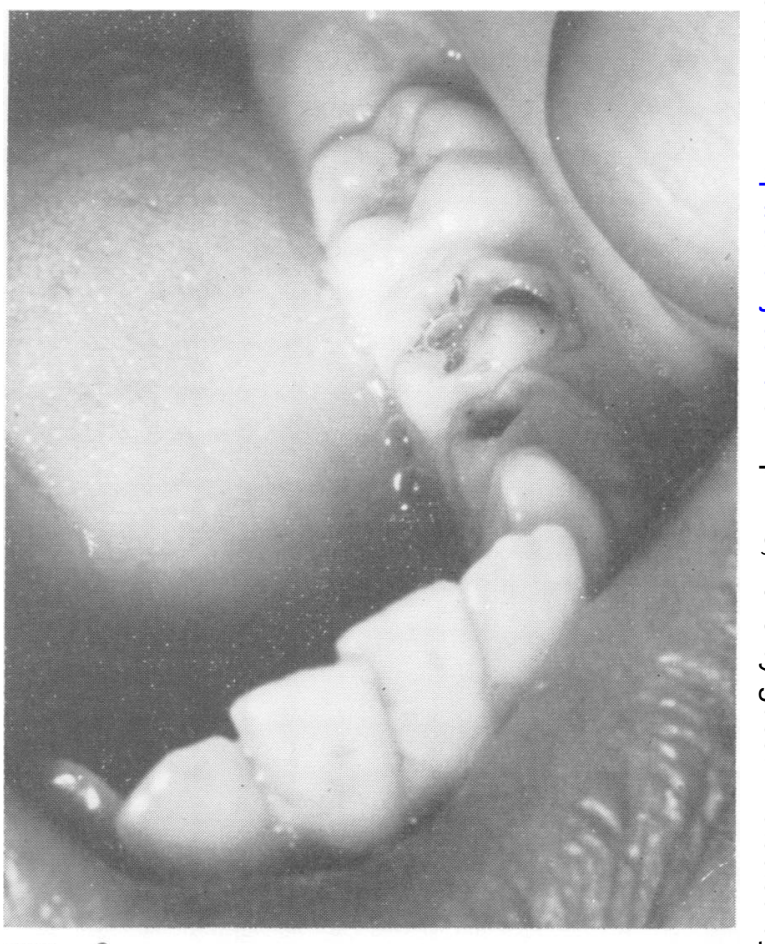

FIG. 3 
In a repeat examination of the boy's blood on June 18, 1970, the TPI, TPHA, FTA-ABS, CWR, VDRL, and RPCF tests gave negative results. On April 6, 1970, the FTA-ABS test only had been positive.

\section{Summary}

The literature concerning the effects of maternal and neonatal treatment on the development of Hutchinson's teeth is reviewed. A boy who had been adequately treated for early congenital syphilis when less than 3 months old was kept under observation for $7 \frac{1}{2}$ years. Hutchinson's teeth developed.

I am indebted to Prof. B. E. D. Cooke, Dean of the Dental School and Professor of Oral Medicine at the Welsh National School of Medicine, for examining the photographs, and to Mr. R. Marshall of the Department of Medical Illustration, Cardiff Royal Infirmary, for taking them.

\section{References}

BRADLAW, R. V. (1953) Oral Surg., 6, 147.

Chief Medical Officer (1970) 'Report for the year 1968 (Appendix, Table C),' Brit. f. vener. Dis., 46, 76

Putkonen, T. (1962) Acta derm.-venereol. (Stockh.), 42, 44 (1963) Ibid., 43, 240

and PAATERo, Y. V. (1961) Brit. F. vener. Dis., 37, 190

Rajam, R. V., and Rangiah, P. N. (1958) Indian f. Derm. Venereol., 24, 85

Stokes, J. H., and Gardner, B. S. (1923) f. Amer. med. Ass., 80, 28

Les dents de Hutchinson et le traitement de syphilis en bas âge

SOMMAIRE

On passe en revue la litérature sur les effets de traitement de la mère et du néonate sur le développement des dents de Hutchinson. Un garçon, atteint de syphilis congénitale a l'âge de moins de trois mois et traité suffisamment à cette époque, a été observé pendant $7 \frac{1}{2}$ ans. Des dents de Hutchinson se sont développées. 